\title{
Burnout among oncology nurses: I nfluence of chronotype and sleep quality
}

\author{
Daniela Bellicoso ${ }^{1}$, Martin R. Ralph ${ }^{1}$, Maureen E. Trudeau ${ }^{2,3}$ \\ 1. Department of Psychology, University of Toronto, Toronto, Ontario, Canada. 2. Division of Medical Oncology and \\ Hematology, Sunnybrook Health Sciences Centre, Toronto, Ontario, Canada. 3. Department of Medicine, University of \\ Toronto, Toronto, Ontario, Canada.
}

Correspondence: Daniela Bellicoso. Address: Department of Psychology, University of Toronto, 100 Saint George Street, Toronto, ON, M5S 3G3, Canada. Email: daniela.bellicoso@utoronto.ca

Received: February 8, 2014

DOI : $10.5430 /$ jnep.v4n8p80
Accepted: April 22, $2014 \quad$ Online Published: June 2, 2014

URL: http://dx.doi.org/10.5430/jnep.v4n8p80

\section{Abstract}

Objective: The study sought to clarify the impact of chronotype and sleep quality on feelings of personal, work-related, and client-related burnout among ambulatory care oncology nurses following regular dayshift work schedules.

Methods: 94 participants from two Toronto, ON hospitals took part. The Horne-Östberg Morningness Eveningness Questionnaire, Pittsburgh Sleep Quality Index, and the Copenhagen Burnout Inventory were used to assess the impact of chronotype and sleep quality, together with subjective measures of job and place of employment satisfaction and work stressfulness on burnout.

Results: Findings showed that participants reporting greater tendency for evening-type or neither-type chronotype, and/or poor sleep quality had significantly higher levels of personal, work-related, and client-related burnout than individuals with either a morning tendency and/or good sleep quality. Work stressfulness also contributed to elevated burnout.

Conclusions: Working at one's optimal time and obtaining good quality sleep contributes to decreased burnout. Future studies should take into account the effect of chronotype and sleep quality on mediating burnout among shift work oncology nurses. When creating nursing work schedules, employees' chronotype and associated sleep quality should be considered to achieve decreased burnout, optimal performance, and potentially increased employee retention and patient care quality and satisfaction.

\section{Key words}

Burnout, Chronotype, Circadian rhythms, Nursing, Oncology, Sleep quality

\section{I ntroduction}

The impacts of chronotype and sleep quality on burnout have yet to be studied and require greater examination. Chronotype reflects one's performance capability as it changes throughout the day and the associated preference for morning (M) vs. evening (E) activities ${ }^{[1,2]}$. Sleep quality refers to both quantitative (e.g., sleep duration and latency, and number of arousals) and subjective (e.g., degree of restfulness) aspects of sleep - however, interindividual differences exist in the elements of sleep composition and their relative importance ${ }^{[3]}$. Healthcare workers are particularly prone to 
burnout, and oncology nurses in general are at great risk, as the uncertainty associated with patient outcome will elevate stress contributing to poor quality sleep ${ }^{[4-6]}$. Given the negative feelings associated with burnout, it is important to understand how chronotype and sleep quality both contribute to, and can be used to alleviate burnout.

Chronotype is associated with a range of outcomes. For example, research has shown systematic differences in blood oxygenation levels in the brain across the day that relate with one's chronotype ${ }^{[7]}$. In terms of measurable behaviour, one's executive functioning and alerting reactions have also shown daily fluctuations that correspond to chronotype ${ }^{[8]}$. Chronotype is linked with the time of sleep onset ${ }^{[1,9]}$. Significant differences in wake and sleep onset times exist between $\mathrm{M}$ and $\mathrm{E}$ type individuals, with $\mathrm{E}$ types going to bed approximately 99 minutes after $\mathrm{M}$ types and awaking approximately 114 minutes after them, without significant differences in each group's sleep duration ${ }^{[1]}$.

Adequate and good quality sleep is a basic human need that is restorative both physically and cognitively ${ }^{[10,11]}$. Like chronotype, sleep quality is also known to affect a range of measurable outcomes. In relation to health, poor sleep quality has been shown to increase many negative physical and mental health problems ${ }^{[12,13]}$. In terms of executive function, good sleep quality has been shown to increase academic performance and executive functioning, while poor sleep quality, particularly among elderly individuals, is associated with reduced cognitive performance ${ }^{[14,15]}$. While proper and adequate sleep is important for everyone, many people do not obtain the necessary amount of slow-wave and REM sleep each night, with approximately $30 \%$ of the general population reporting sleep problems ${ }^{[16]}$. While the concept of sleep quality is difficult to define objectively, it does involve certain key quantitative and subjective constructs such as sleep duration and restfulness, respectfully ${ }^{[3]}$. Shortened sleep duration impedes physical and cognitive restoration, and decreases the following day's wakefulness, while regularly oversleeping can increase tiredness due to the strenuous and energy consuming nature of REM sleep ${ }^{[17]}$. Sleep restfulness relies both on the quality of one's previous waking period and its ability to generate proper homeostatic sleep drive, and how one perceived their personal level of tiredness following a sleep period ${ }^{[18]}$. Thus, sleep quality - based both on its quantitative and subjective aspects, is important in allowing a person to go through the sleep stages necessary for their body to be properly restored, well rested, and ready for the next day. However, while the importance of adequate and good quality sleep has been studied abundantly, many conventional societal practices interfere with achieving proper sleep quality when they conflict with the hours associated with innate chronotype.

Work schedules in continuous disharmony with one's circadian rhythm induce stress, which negatively affects sleep quality ${ }^{[10]}$. Disturbed sleep and its associated fatigue make it difficult to carry out daily activities and work tasks. Among nurses, sleep debt induces stress independently of the high stress work situations they face on a daily basis, oftentimes leading to feelings of extreme emotional and physical fatigue, decreased cognitive function, weariness, and exhaustion, which together are known as burnout ${ }^{[1,20]}$.

Burnout is determined from feelings of emotional and physical fatigue or exhaustion, cognitive weariness, and chronic energy resource depletion due to continued exposure to stress. However, there is no concrete definition of the term, nor is there a standardized general procedure from which to obtain a burnout diagnosis ${ }^{[19,21]}$. A common hypothesis is that stress-induced sleep disturbances over time compound to produce mental and physical exhaustion, which are generally agreed to be key contributors to burnout ${ }^{[22]}$. In line with this hypothesis, the Copenhagen Burnout Inventory (CBI) used in the present study suggests that at the core of burnout are fatigue and exhaustion ${ }^{[23]}$. The CBI subscribes to the definition of burnout that suggests it is a state of emotional, physical, and mental exhaustion resulting from prolonged involvement in emotionally demanding work situations ${ }^{[24]}$. In healthcare organizations, burnout is a significant phenomenon due to its demonstrated negative effects on patient satisfaction and safety, and on nurse retention and turnover ${ }^{[6]}$. Among clinical care oncology nurses, higher burnout rates have been found compared to hospice care oncology nurses, suggesting that working in a hospital setting with the goal to heal sick patients rather than care for those that are dying, may increase stress levels, and cause subsequent sleep disturbances which may contribute to the gap in burnout reports ${ }^{[25]}$. 
While many studies have examined the triggers and protective factors for burnout, the influence of chronotype and sleep quality on this phenomenon have not been studied. We sought to demonstrate the potential for chronotype and sleep quality to mediate feelings of burnout among ambulatory care oncology nurses working in a hospital setting on a fixed Monday to Friday daytime work schedule by using a set of standardized questionnaires to assess the influence of chronotype and sleep quality on burnout. Our objectives were to understand the separate links between good versus bad sleep and one's ratings of the various types of burnout, and the link between chronotype and burnout. It was also important to understand the differential contribution of various predictors (chronotype, sleep quality, job satisfaction, overall place of employment satisfaction, and work stressfulness) on the various types of burnout. It was predicted that M types and respondents with better sleep would exhibit less overall burnout compared to E types and people reporting poor sleep quality. It was also predicted that in addition to one's chronotype and sleep quality, stressfulness and satisfaction ratings relating to one's job would differentially influence each type of burnout.

\section{Methods}

\subsection{Participants}

Registered ambulatory care oncology nurses working at one of two primary care hospitals in Toronto, Ontario, Canada University Health Network Princess Margaret Cancer Centre (PMH), and Sunnybrook Health Sciences Centre Odette Cancer Centre (SB) - were recruited to participate. A total of 64 nurses completed questionnaires with useable results (PMH, $n=42$, all female, age $27-63$, mean age 45.29 \pm 10.18 ; SH, $n=22,21$ females, 1 male, age $28-65$, mean age $50.54 \pm 11.70$ ). The mean ages for these groups are not significantly different (see Table 1). Inclusion criteria were as follows: participants must be ambulatory care oncology nurse responsible for the care and support of oncology patients, be currently employed in one of the hospitals, follow a regular dayshift work schedule Monday to Friday, and not be connected with the present study. The study was granted approval by the ethics committees of both hospitals. Informed consent was obtained from all participants prior to giving them the questionnaire package. Study participation was voluntary.

\subsection{Procedure}

A preliminary meeting was held to present the aims of the study, and an anonymous survey package was distributed to nurses who agreed to partake in the present study. Time was given in the meeting to complete the survey package. Nurses provided demographic information and job descriptions (age, gender, job satisfaction, place of employment satisfaction, and stressfulness of current job) in a background information survey.

\subsection{Measures}

The Horne-Östberg Morningness Eveningness Questionnaire (MEQ) is a 19-item measure that was used to assess tendency for $\mathrm{M}$ or $\mathrm{E}$ chronotype. Each component question is scored on a scale in the range of $0-6$ depending on the question, based on guidelines provided by the questionnaire's authors, to obtain a global score between 16 and 86 . Based on one's global score, a rating of definitely E- (16 to 30), moderately E- (31 to 41), neither- (42 to 58), or moderately M(59 to 69) or definitely M-type (70-86) is given.

The Pittsburgh Sleep Quality Index (PSQI) is a 19-item measure that yields a global sleep quality index. Each question is scored on a frequency scale of 0 to 3 ( 0 indicates no occurrence of a particular sleep disturbance). A global sleep quality rating is provided on a scale of 0 to 21 (following data transformations), where a global score of $\leq 5$ indicates good sleep quality, while $>5$ indicates poor sleep quality.

The primary outcome variables - personal, work-related, and client-related burnout - were measured using the Copenhagen Burnout Inventory (CBI) which is a 3-scale, 19-item measure used to assess these 3 types of burnout that 
provides a corresponding burnout score for each category. Each component question is rated with a score of $0,25,50,75$ or 100. Total scores for each burnout category are based on the mean of the component questions pertaining to that section. The higher a scale's associated score, the greater the degree of burnout that is associated with that specific dimension.

\subsection{Statistical analysis}

A priori tests indicated that to detect a moderate effect size, with $80 \%$ power and $\alpha=.05$, sample size calculations for a one-tailed test required 27 subjects. Statistical analyses were performed using SPSS (Statistical Package for the Social Sciences) version 20.0 for Mac. Analyses were run as follows: demographic and test variables of the two hospital groups of nurses were compared using unpaired $t$-tests. Each group of nurses was analyzed by their MEQ classification, and again by the PSQI good or poor quality sleep rating using $t$-tests to look for burnout differences. Correlations were run between the test variables to help determine where significant associations lay between different items. Lastly, multivariate regression analyses were run to clarify the differential contribution of the predictors of interest to the outcome measures. A $p$ value $<.05$ was accepted as statistically significant.

\section{Results}

Of the 94 nurses who volunteered to participate, 64 (68.09\%) provided useable data, resulting in a strong effect size with 98.96\% power ( $\alpha=.05$, one-tailed test). At PMH, $42 / 60$ (70.00\%) returned useable data, while 22/34 (64.71\%) with useable data were returned from SH. None of the demographic characteristics and questionnaire response ratings between the two groups are statistically different for these categories, indicating that the two groups are well matched (see Table 1).

Table 1. Demographic characteristics and questionnaire response ratings of participants

\begin{tabular}{|c|c|c|c|}
\hline & \multicolumn{2}{|l|}{ Nurse group } & \multirow[b]{2}{*}{$t$-test* } \\
\hline & $\begin{array}{l}\text { PMH } \\
(n=42)\end{array}$ & $\begin{array}{l}\text { SB } \\
(n=22)\end{array}$ & \\
\hline Age in years $(\mathrm{SD})$ & $45.29(10.18)$ & $50.54(11.70)$ & NS \\
\hline Gender (M:F) & $0: 42$ & $1: 21$ & - \\
\hline Oncology nurse experience (yrs) (SD) & $15.10(11.64)$ & $14.19(10.25)$ & NS \\
\hline Job satisfaction $(\mathrm{SD})$ & $3.46(1.09)$ & $3.93(0.76)$ & NS \\
\hline Overall place of employment satisfaction (SD) & $3.70(1.01)$ & $4.05(0.95)$ & NS \\
\hline Work stressfulness (SD) & $3.82(1.03)$ & $3.68(1.09)$ & NS \\
\hline MEQ (SD) & $57.02(8.47)$ & $59.82(9.52)$ & NS \\
\hline PSQI (SD) & $6.60(3.59)$ & $5.50(2.20)$ & NS \\
\hline CBI (personal) (SD) & $50.20(19.63)$ & $44.32(16.94)$ & NS \\
\hline CBI (work) (SD) & $51.70(22.16)$ & $44.48(16.52)$ & NS \\
\hline CBI (client related) (SD) & $21.33(19.13)$ & $21.02(14.52)$ & NS \\
\hline
\end{tabular}

Note. $\mathrm{NS}=$ not significant. ${ }^{*} p<.05,2$-tailed.

The three separate CBI categories each conceptualize burnout as a continuous variable on a scale of 0 to 100 . Table 2 shows burnout ratings among respondents with good $(\leq 5)$ or poor $(>5)$ sleep quality as rated by the PSQI, and burnout ratings among MEQ types. Given the low number of moderately E types $(n=2)$ and definitely M types $(n=4)$, these two categories have been added to the neither type and moderately $\mathrm{M}$ type groups, respectively. This break point also allows for a nearly equal frequency distribution of participants with $48.44 \%$ of respondents qualifying as moderately $\mathrm{E}$ type or neither type, and $51.56 \%$ qualifying as $\mathrm{M}$ types. It is important to note that while both of these conceptualizations of burnout in Tables 2 are broken down into groups of $n=31$ and $n=33$, the individuals making up these divisions are not necessarily the same across both sets of data. 
Table 2. Comparison of burnout ratings between respondents with good and bad sleep quality and between MEQ types

\begin{tabular}{|c|c|c|c|c|c|c|}
\hline & \multicolumn{3}{|l|}{ Sleep quality } & \multicolumn{3}{|l|}{ MEQ } \\
\hline & $\begin{array}{l}\text { Good } \\
(\text { PSQI } \leq 5) \\
(n=31)\end{array}$ & $\begin{array}{l}\text { Bad } \\
(\text { PSQI }>5) \\
(n=33)\end{array}$ & $t$-test & $\begin{array}{l}\text { Moderately \& } \\
\text { Definitely M type } \\
(n=33)\end{array}$ & $\begin{array}{l}\text { Moderately } \\
\text { E \& } \\
\text { Neither type } \\
(n=31)\end{array}$ & t-test \\
\hline CBI (personal) (SD) & $39.65(18.81)$ & $56.19(15.13)$ & $-3.88 * * *$ & $42.17(21.16)$ & $54.57(13.58)$ & $2.78 * *$ \\
\hline CBI (work) (SD) & $42.51(21.77)$ & $55.52(17.41)$ & $-2.65 * *$ & $42.86(22.23)$ & $55.99(16.38)$ & $2.68 * *$ \\
\hline CBI (client related) (SD) & $15.59(15.51)$ & $26.52(17.94)$ & $-2.60 *$ & $15.15(16.23)$ & $27.69(16.82)$ & $3.03 * *$ \\
\hline
\end{tabular}

$* p<.05,2$-tailed. $* * p<.01,2$-tailed. $* * * p<.001,2$-tailed.

As shown in Table 3, MEQ and PSQI scores are not significantly correlated. Significant correlations exist between all CBI scores and the associated MEQ and PSQI scores. Stressfulness associated with place of employment is significantly correlated to all burnout subscales, while job satisfaction is significantly correlated only with work related burnout. Overall place of employment satisfaction was not correlated with chronotype, sleep quality, or any of the burnout ratings.

Table 3. Analysis of bivariate correlations for participants' questionnaire response ratings

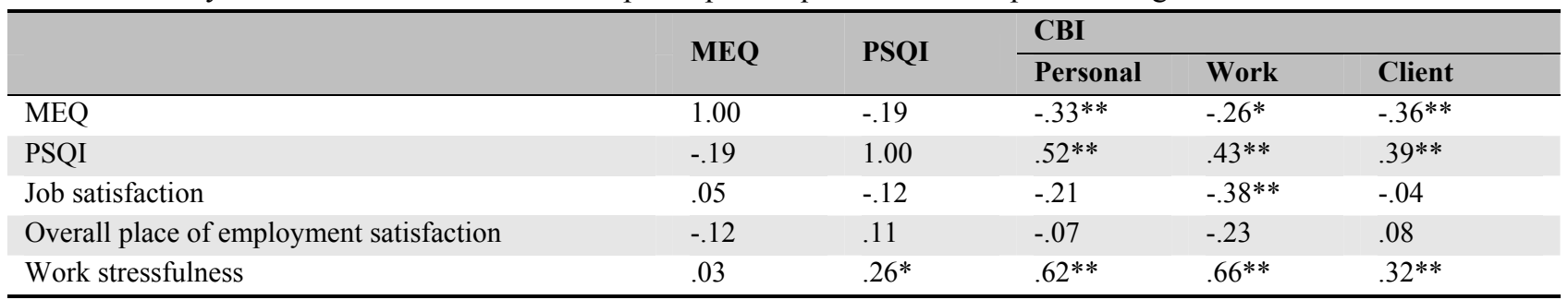

$* p<.05$, 2-tailed. $* * p<.01,2$-tailed.

To clarify the differential contribution of the predictors of interest on the various categories of burnout, multivariate regression analyses were run. Table $4 \mathrm{a}$ shows the relationship between personal burnout and each predictor. Statistical model \#2 (Step 2) yields a satisfactory proportion of variances explained, as indicated by the associated $R^{2}$ value (.61). Table $4 \mathrm{~b}$ shows the relationship between work related burnout and each predictor. For this relationship, statistical model \#3 (Step 2) yields a satisfactory proportion of variances explained as indicated by the associated $R^{2}$ value (0.62). Table 4c shows the relationship between client related burnout and each predictor. For this relationship, statistical model \#2 (Step 2) yields a satisfactory proportion of variances explained as indicated by the associated $R^{2}$ value $(0.31)$. Note that the $R^{2}$ value explaining the proportion of variance for client related burnout due to these predictors is much lower than that seen for personal and work related burnout. This suggests that other factors not being considered in this study may influence client related burnout.

Table 4a. Summary of hierarchical multivariate regression analysis for variables predicting personal burnout among oncology nurses $(\mathrm{N}=64)$

\begin{tabular}{llll}
\hline Variables & $\boldsymbol{b}$ & $\boldsymbol{S E} \boldsymbol{b}$ & $\boldsymbol{B}^{\mathbf{a}}$ \\
\hline Step 1 & & & $-.24 *$ \\
Constant & 60.91 & 14.56 & $.47 * * *$ \\
MEQ & -0.52 & 0.23 & 0.63 \\
PSQI & 2.77 & & $.29 * * *$ \\
Step 2 & & 11.93 & $.32 * * *$ \\
Constant & 34.52 & 0.18 & $.55^{* * *}$ \\
MEQ & -0.61 & 0.50 & 1.51 \\
PSQI & 1.90 & 9.88 & \\
Work Stressfulness & & & \\
\hline
\end{tabular}

Note. $R^{2}=.33$ for step $1 ; \Delta R^{2}=.28$ for step $2 .{ }^{\text {a }}$ standardized coefficient $* p<.05,2$-tailed. $* * * p<.001,2$-tailed. 
Table 4b. Summary of hierarchical multivariate regression analysis for variables predicting work related burnout among oncology nurses $(\mathrm{N}=64)$

\begin{tabular}{llll}
\hline Variables & $\boldsymbol{b}$ & $\boldsymbol{S E} \boldsymbol{b}$ & $\boldsymbol{B}^{\mathbf{a}}$ \\
\hline Step 1 & 58.18 & 17.39 & -.18 \\
Constant & -0.43 & 0.27 & $.39^{* * *}$ \\
MEQ & 2.52 & 0.74 & \\
PSQI & & & 13.70 \\
Step 2 & 26.07 & 0.20 & $.23^{* *}$ \\
Constant & -0.54 & 0.58 & $.23^{*}$ \\
MEQ & 1.46 & $.61^{* * *}$ \\
PSQI & 12.04 & 1.74 & $-.22^{* *}$ \\
Work Stressfulness & & & $.21^{*}$ \\
Step 3 & 45.41 & 14.72 & $.57^{* * *}$ \\
Constant & -0.52 & 0.19 & $-.23^{* *}$ \\
MEQ & 1.37 & 0.55 & 1.68 \\
PSQI & 11.20 & 1.68 & \\
Work Stressfulness & -4.69 & .05 for step 3. ${ }^{a}$ standardized coefficient &
\end{tabular}

Table 4c. Summary of hierarchical multivariate regression analysis for variables predicting client related burnout among oncology nurses $(\mathrm{N}=64)$

\begin{tabular}{llll}
\hline Variables & $\boldsymbol{b}$ & $\boldsymbol{S E} \boldsymbol{b}$ & $\boldsymbol{B}^{\mathbf{a}}$ \\
\hline Step 1 & & & \\
Constant & 44.00 & 14.23 & $-.30^{*}$ \\
MEQ & -0.59 & 0.23 & $.33^{* *}$ \\
PSQI & 1.84 & 0.63 & $.32^{* *}$ \\
Step 2 & & & $.26^{*}$ \\
Constant & 32.03 & 14.77 & $.27^{*}$ \\
MEQ & -0.63 & 0.22 & 0.62 \\
PSQI & 1.44 & 1.88 & \\
Work Stressfulness & 4.49 & &
\end{tabular}

Note: $R^{2}=.24$ for step $1 ; \Delta R^{2}=.07$ for step $2 .^{a}$ standardized coefficient

$* p<.05$, 2-tailed. $* * p<.01,2$-tailed.

According to the experimental hypothesis, chronotype and sleep quality significantly influenced all the CBI subscale scores. In addition, each respondent's perception of work stressfulness significantly influenced each CBI subscale score. Job satisfaction was a significant factor influencing the work related CBI subscale. These findings correspond with the analysis of bivariate correlations indicated in Table 3 .

\section{Discussion}

Chronotype and sleep quality are known to influence a wide range of important aspects of daily life such as physical and mental health, blood oxygenation, and cognitive functioning to name a few ${ }^{[7,13,15]}$. However, the influence of one's chronotype and sleep quality on the degree of burnout has not been greatly explored. Given the high degree of burnout associated with several careers, and particularly with oncology nursing, it was important to consider the impacts of chronotype and sleep quality on burnout. This information will be informative to the design of schedules and approaches that reduce burnout among members of this group. The present study investigated the contribution of chronotype and sleep 
quality, together with situational factors, on symptoms of burnout among ambulatory care oncology nurses working in outpatient clinics in one of two hospitals in Toronto, Ontario, Canada. It was found that innate chronotype and sleep quality strongly predicted burnout, such that individuals with an $\mathrm{M}$ type tendency, and respondents with better sleep quality, experienced less burnout when following a set dayshift work schedule.

The two groups of nurses from each hospital were well matched for demographic characteristics. A comparison of the two nurse groups found the absence of a significant difference in terms of job satisfaction, overall place of employment satisfaction, place of employment stressfulness, age, and years as a nurse, thus ruling out the possibility that burnout was triggered by place of employment satisfaction differences. The two groups were also well matched for their MEQ and PSQI scores.

No significant difference was found between the two nurse groups, regarding the presence of feelings of personal, work-related, and client-related burnout as rated by the CBI. However, significant differences in tendency for feelings of burnout were found between individuals reporting good versus poor sleep quality based on PSQI cutoff ratings. Respondents with good sleep quality reported significantly lower levels of burnout across all three subscales, compared to participants who described themselves as having poor quality sleep. Regarding chronotype, individuals with a greater propensity for morningness reported lower levels of burnout across all three subscales compared to participants with a tendency for eveningness or neither M nor E. In both cases of burnout analysis - by sleep quality and by chronotype personal and work related burnout were reported to be in the midrange level of severity, while client-related burnout appeared to be much lower. It is possible that client related burnout may have been reported as being much lower than personal and work related burnout scores if nurses are inclined to express compassion towards patients as opposed to being frustrated with them. However, no data was collected on this topic therefore no formal conclusions can be drawn. In the future, it will be important to look at both compassion fatigue and compassion satisfaction to examine changes in nurses' feelings on these topics as they relate to chronotype and sleep quality.

In agreement with the idea by Söderström et al. ${ }^{[22]}$ that stress and sleep quality are associated, correlational analysis demonstrated that individuals expressing greater work stressfulness tend to have poorer sleep quality. Interestingly however, while the data were not shown, chronotype and sleep quality were not associated in this sample. This may be due in part to the sample size. Had more extreme chronotypes been obtained, this may have led to an association. Furthermore, this result may change if sleep quality and chronotype were to be examined in shiftworkers. It is more likely that in such a group, people would be working at hours that may significantly conflict with their chronotype, or if they are extreme $\mathrm{M}$ or E types, may even compliment them. Furthermore, shiftworkers likely have fragmented sleep which would affect their sleep quality ratings, and this together with chronotype, might yield different results on the relationship between chronotype and sleep quality.

To further investigate the evidence supporting the significant contribution made by chronotype tendency, sleep quality, job satisfaction, place of employment satisfaction, and overall place of employment stressfulness, in determining feelings of burnout, multivariate regression analyses were applied. Chronotype tendency and sleep quality were significant factors influencing all of the CBI subscale scores, however, here again the effect of these two factors on client related burnout was much less than on personal and work-related burnout. As such, it appears that both propensity for morningness and good sleep quality lower the risk of burnout among oncology nurses working regular day shifts Monday to Friday. Overall workplace stressfulness was a contributor to each burnout subscale score, indicating that reduced workplace stressfulness protects against each type of burnout examined by this study. Job satisfaction also contributes significantly to workplace related burnout, suggesting that higher job satisfaction leads to reduced burnout in this domain. It did not however, influence personal or client related burnout. Overall place of employment satisfaction was not a significant contributing factor, suggesting that one's burnout is more so influenced by the specific role or duties they must carry out, rather than by the institution as a whole. The lack of correlation between overall place of employment satisfaction and any of the burnout 
ratings supports the finding that overall place of employment satisfaction was not a differential predictor for any of the burnout ratings examined.

According to the experimental hypothesis, this study's findings support the view that chronotype and sleep quality are key predictors of personal, work-related, and client-related burnout symptoms, indicating that oncology nurses following a permanent dayshift schedule with a propensity for morningness present with relatively low levels of burnout, compared to their colleagues working at the same time but who have a tendency for eveningness or neither type of chronotype. Furthermore, ambulatory care oncology nurses obtaining better sleep quality also experience significantly decreased feelings of burnout across all three domains as compared to their colleagues who report poor sleep quality. Many people either through necessity or voluntarily - work at times that conflict with their chronotype, oftentimes foregoing adequate sleep in order to do so. This results in poorer sleep quality for a number of reasons including but not limited to shortened sleep, going to bed at times not reflective of one's chronotypic needs, and even sleeping at times of day when one should actually be awake and functioning, to name a few. While other personal and environmental factors likely also underlie these significant burnout differences, allowing nurses to begin work at slightly modified times that better accommodate their chronotypic needs and may help modify or enhance their sleep situation and quality, might significantly help to reduce levels of personal, work related, and client related burnout. However, further studies need to be completed in order to understand which of these burnout subscale categories would be more or less affected by such changes.

This study's results have important implications in the healthcare profession, not only regarding nurse related burnout, but also relating to patient care. If burnout brings on feelings of cognitive weariness, one's decision-making skills may be affected such that their ability to make sound judgments may be hindered by increased feelings of burnout. Physical and emotional fatigue may also be heightened, potentially reducing one's ability to react quickly in dire situations to help a patient in distress. Emotional control or regulation may also be compromised, which could elevate a patient's level of distress should they be forced to deal with a nurse who is emotionally burnt out. Burnout is known to increase the risk of absence from work ${ }^{[26]}$. An increasing number of people absent from work due to burnout will further compound the workload and related stress felt by many nurses working in the same department who will need to take over the responsibilities of their coworkers. Based on these negative effects of burnout, it is in a medical institution's best interest to consider how key contributors such as chronotype and sleep quality can be better managed and used to alleviate symptoms of burnout. Given the large number of nurses following shift work schedules both in and out of the field of oncology, future studies should address burnout among oncology nurses engaging in shift work in order to understand how chronotype and sleep quality could be used to structure schedules that allow for decreased reports of burnout.

\section{Limitations}

One limitation of this study is related to sample size. Future studies using larger numbers may likely be able to achieve a greater and more equal distribution of $\mathrm{E}$ and $\mathrm{M}$ type participants. This might allow for reanalysis of the current statistics in this study that suggest there is no correlation between chronotype and sleep quality among oncology nurses, as well as a greater understanding of how extreme the symptoms of burnout are among E type participants working earlier in the day. Secondly, in the future it would be beneficial to study client-related burnout, by including other objective measures to rate one's degree of compassion, in order to understand if reduced ratings in this domain are related to feelings of compassion for patients, or whether some other factor was involved in causing nurses to report such markedly lower burnout level in this domain. The role of other factors such as extracurricular activities, medical conditions, and medications were not investigated, as many nurses did not report this information in the personal survey, and it would be important to understand the role of these variables in future.

\section{Conclusion}

Individual chronotype and sleep quality are important determinants of alertness and cognitive ability variance throughout the day. The findings of this study help to clarify the contributions of chronotype and sleep quality to burnout, together 
with workplace stressfulness and job satisfaction, and as such fully support initiatives for programs that would modify work schedules to accommodate the needs of one's chronotype and that would also make suggestions for modifications that would ameliorate one's sleep quality. Such initiatives would result in decreased burnout among ambulatory oncology nurses, and may subsequently increase quality of patient care and satisfaction. This research also presents further research opportunities for understanding burnout among oncology nurses following shift work schedules, by considering the disruption their work brings to their circadian rhythm and sleep quality.

\section{Acknowledgment}

We wish to thank the oncology nurses who kindly volunteered their time to participate in the study. We thank Dr. M. Fitch for her suggestions while preparing this manuscript. We thank Dr. N. Leighl and Ms. B. Fitzgerald for making an introduction to the oncology nurses at PMH.

\section{Competing interests}

The authors declare that they have no competing interests.

\section{References}

[1] Horne JA, Östberg O. A self-assessment questionnaire to determine morningness-eveningness in human circadian rhythms. Int J Chronobiol. 1976; 4(2): 97-110. PMid: 1027738

[2] Nielsen T. Nightmares associated with the eveningness chronotype. J Biol Rhythms. 2010; 25(1): 53-62. PMid: 20075301 http://dx.doi.org/10.1177/0748730409351677

[3] Buysse, DJ, Reynolds III, CF, Monk, TH, Berman, SR, Kupfer, DJ. The Pittsburgh sleep quality index: a new instrument for psychiatric practice and research. Psychiatry Res. 1989; 28(2): 193-213. PMid: 2748771 http://dx.doi.org/10.1016/0165-1781(89)90047-4

[4] Chen SM, McMurray A. "Burnout" in intensive care nurses. J Nurs Res. 2001; 9(5):152-164. PMid: 11779088

[5] Cubrilo-Turek M, Urek R, Turek S. Burnout syndrome - assessment of a stressful job among intensive care staff. Coll Antropol. 2006; 30(1): 131-135. PMid: 16617587

[6] Potter P, Deshields T, Divanbeigi J, Berger J, Cipriano D, Norris L, et al. Compassion fatigue and burnout: prevalence among oncology nurses. Clin J Oncol Nurs. 2010; 14(5): E45-E62. PMid: 20880809 http://dx.doi.org/10.1188/10.CJON.E56-E62

[7] Peres I, Vetter C, Blautzik J, Reiser M, Pöppel E, Meindl T, et al. Chronotype predicts activity patterns in the neural underpinnings of the motor system during the day. Chronobiol Int. 2011; 28(10): 883-889. PMid: 22080733

http://dx.doi.org/10.3109/07420528.2011.619084

[8] Matchock RL, Mordkoff JT. Chronotype and time-of-day influences on the alerting, orienting, and executive components of attention. Exp Brain Res. 2009; 192(2): 189-198. PMid: 18810396 http://dx.doi.org/10.1007/s00221-008-1567-6

[9] Roenneberg T, Wirz-Justice A, Merrow M. Life between clocks: daily temporal patterns of human chronotypes. J Biol Rhythms. 2003; 18(1):80-90. PMid: 12568247 http://dx.doi.org/10.1177/0748730402239679

[10] Karagozoglu S, Bingöl N. Sleep quality and job satisfaction of Turkish nurses. Nurs Outlook. 2008; 56(6): 298-307, $307 . e 1-. e 3$. PMid: 19041451 http://dx.doi.org/10.1016/j.outlook.2008.03.009

[11] Stepanski EJ. The effect of sleep fragmentation on daytime function. Sleep 2002; 25(3): 268-276. PMid: 12003157

[12] Araghi MH, Jagielski A, Neira I, Brown A, Higgs S, Thomas GN, Taheri S. The complex associations among sleep quality, anxiety-depression, and quality of life in patients with extreme obesity. Sleep. 2013; 36(12): 1859-1865. PMid: 24293760 http://dx.doi.org/10.5665/sleep.3216

[13] Fujiwara Y, Habu Y, Ashida K, Kusano M, Higuchi K, Arakawa T. Sleep disturbances and refractory gastroesophageal reflux disease symptoms in patients receiving once-daily proton pump inhibitors and efficacy of twice-daily Rabeprazole treatment. Digestion. 2013; 88(3): 145-152. PMid: 24008338 http://dx.doi.org/10.1159/000354071

[14] Lemma S, Berhane Y, Worku A, Gelaye B, Williams MA. Good sleep quality is associated with better academic performance among university students in Ethiopia. Sleep Breath. 2013; in press. PMid: 23928956

[15] Miyata S, Noda A, Iwamoto K, Kawano N, Okuda M, Ozaki N. Poor sleep quality impairs cognitive performance. J Sleep Res. 2013; 22(5): 535-541. PMid: 23560612 http://dx.doi.org/10.1111/jsr.12054 
[16] van Litsenburg RR, Huisman J, Hoogerbrugge PM, Egeler RM, Kaspers GJ, Gemke RJ. Impaired sleep affects quality of life in children during maintenance treatment for acute lymphoblastic lymphoma: an exploratory study. Health Qual Life Outcomes. 2011; 9: 25-31. PMid: 21496357 http://dx.doi.org/10.1186/1477-7525-9-25

[17] Bonnet MH, Arand DL. We are chronically sleep deprived. Sleep 1995; 18(10):908-911. PMid: 8746400

[18] Bersagliere A, Raduazzo ID, Nardi S, Gatta A, Amodio P, Achermann P, et al. Induced hyperammonemia may compromise the ability to generate restful sleep in patients with cirrhosis. Hepatology. 2012; 55(3): 869-878. PMid: 21994139 http://dx.doi.org/10.1002/hep. 24741

[19] Brand S, Beck J, Hatzinger M, Harbaugh A, Ruch W, Holsboer-Trachsler E. Associations between satisfaction with life, burnout-related emotional and physical exhaustion, and sleep complaints. World J Biol Psychiatry. 2010; 11(5):744-754. PMid: 20331383 http://dx.doi.org/10.3109/15622971003624205

[20] Vela-Bueno A, Moreno-Jiménez B, Rodríguez-Muñoz A, Olavarrieta-Bernardino S, Fernández-Mendoza J, De la Cruz-Troca, JJ, et al. Insomnia and sleep quality among primary care physicians with low and high burnout levels. J Psychosom Res 2008; 64(4):435-442. PMid: 18374744 http://dx.doi.org/10.1016/j.jpsychores.2007.10.014

[21] Korczak D, Huber B, Kister C. Differential diagnostic of the burnout syndrome. GMS Health Technol Assess. 2010, 6: Doc09(1-9). PMid: 21289882 http://dx.doi.org/10.3205/hta000087

[22] Söderström M, Ekstedt M, Åkerstedt T, Nilsson, J, Axelsson J. Sleep and sleepiness in young individuals with high burnout scores. Sleep. 2004; 27(7): 1369-1377. PMid: 15586790

[23] Kristensen TS, Borritz M, Villadsen E, Christensen KB. The Copenhagen burnout inventory: a new tool for the assessment of burnout. Work Stress. 2005; 19(3): 192-207. http://dx.doi.org/10.1080/02678370500297720

[24] Schaufeli WB, Greenglass ER. Introduction to special issue on burnout and health. Psychol Health. 2001; 16(5): 501-510. PMid: $22804495 \mathrm{http} / / / \mathrm{dx}$.doi.org/10.1080/08870440108405523

[25] Ostacoli L, Cavallo M, Zuffranieri M, Negro M, Sguazzotti E, Picci, RL, et al. Comparison of experienced burnout symptoms in specialist oncology units or in hospices. Palliat Support Care. 2010; 8(4):427-432. PMid: 20875206 http://dx.doi.org/10.1017/S1478951510000295

[26] Westermann C, Kozak A, Harling M, Nienhaus A. Burnout intervention studies for inpatient elderly care nursing staff: systematic literature review. Int J Nurs Stud 2014; 51(1):63-71. PMid: 23273537 http://dx.doi.org/10.1016/j.ijnurstu.2012.12.001 